\title{
Selective Coupling of Bioderived Aliphatic Alcohols with Acetone Using Hydrotalcite Derived Mg-Al Porous Metal Oxide and Raney Nickel
}

\author{
Bálint Fridrich, ${ }^{\dagger}$ Marc C. A. Stuart, ${ }^{\ddagger}$ and Katalin Barta* ${ }^{\dagger}{ }^{\dagger}$ \\ ${ }^{\dagger}$ Stratingh Institute for Chemistry, University of Groningen, Nijenborgh 4, 9747 AG Groningen, The Netherlands \\ ${ }^{\ddagger}$ Department of Electron Microscopy, Groningen Biomolecular Sciences and Biotechnology Institute, University of Groningen, \\ Nijenborgh 7, 9747 AG Groningen, The Netherlands
}

\section{Supporting Information}

ABSTRACT: Fermentation of sugars to the so-called ABE mixture delivers a three component mixture of shorter chain oxygenates: acetone, $n$-butanol and ethanol. In order to convert these into liquid transportation fuels that are analogous to the currently used fossil energy carriers, novel catalytic chain elongation methods involving

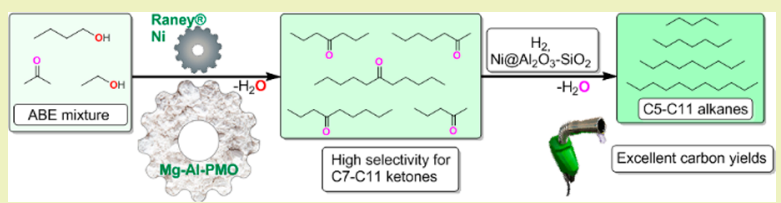
$\mathrm{C}-\mathrm{C}$ bond formation are desired. Herein we report on a simple, non-noble-metal-based method for the highly selective coupling of 1-butanol and acetone into high molecular weight (C7-C11) ketones, as well as $\mathrm{ABE}$ mixtures into $(\mathrm{C} 5-\mathrm{C} 11)$ ketones using the solid base $\mathrm{Mg}-\mathrm{Al}-\mathrm{PMO}$ in combination with small amount of Raney nickel. Upon hydrodeoxygenation, these ketones are converted to fuel range alkanes with excellent carbon utilization (up to 89\%) using Earth abundant metal containing catalysis.

KEYWORDS: Bioethanol, 1-Butanol, ABE mixture, Raney nickel, Porous metal oxides

\section{INTRODUCTION}

Lignocellulosic biomass is a globally available, carbon-neutral, renewable resource that does not compete with the food supply and that could, in principle, provide suitable and sustainable alternatives to the fossil-based chemicals currently made. ${ }^{1-3}$ It could also be used to produce liquid transportation fuels that are, in their chemical structure, analogous to the generally utilized petroleum derived sources and are therefore fully compatible with existing infrastructures. ${ }^{4}$ However, the conversion of naturally abundant carbohydrates to fuel-range hydrocarbons (>C8) is not straightforward, because the central monosaccharide building block, D-glucose only consists of six carbon atoms. ${ }^{5}$ Thus, beside appropriate downstream processing of the sugar platform, also novel methods for $\mathrm{C}-\mathrm{C}$ bond formation and subsequent deoxygenation are desired. ${ }^{6-8}$

Fermentation of sugars to produce ethanol is a historically well-established method ${ }^{9,10}$ that is also significant today for the production of first and second generation bioethanol. ${ }^{11,12}$ Another interesting biochemical transformation of cellulosic or noncellulosic feedstocks is the so-called ABE (acetone, butanol, ethanol) fermentation, ${ }^{13,14}$ which provides a three component mixture of these small molecular weight oxygenates. ${ }^{15}$ Pioneering work from the Toste group has presented an integrated approach that combines fermentation of sugars to $\mathrm{ABE}$ mixture that is subsequently catalytically converted to yield C5-C11 ketones and ultimately high energy density $(30.2-35 \mathrm{MJ} / \mathrm{L})$, fuel range alkanes with excellent carbon balance. ${ }^{16}$ Their approach recognized the potential of acetone to readily undergo aldolcondensation with the aldehydes in situ generated from the primary alcohols in the $\mathrm{ABE}$ mixture. The required dehydrogen- ation, aldol condensation and hydrogenation sequence was performed using the physical mixture of $\mathrm{Pd} @ \mathrm{C}$ and $\mathrm{K}_{3} \mathrm{PO}_{4}$ to yield chain elongated ketones. Next, the group introduced recyclable hydrotalcite-based catalyst doped with various metals. ${ }^{17}$ Later, a synergistic effect was found in a $\mathrm{Pd} / \mathrm{Cu}$ doped hydrotalcite that allowed for high product selectivity at $200{ }^{\circ} \mathrm{C}$ in the gas phase. ${ }^{18} \mathrm{An}$ in depth study of the hydrogenation and decarbonylation of butanal over various $\mathrm{PdCu}$ bimetallic catalysts comprising different supports was conducted. ${ }^{19}$ Further, it was observed that HTC doped with up to $2.5 \% \mathrm{Cu}$ (prepared by impregnation), upon calcination, leads to excellent reaction rates. ${ }^{20}$ Other groups also found excellent results in this and related reactions, such as the palladium catalyzed chain elongation of diluted aqueous $\mathrm{ABE}$ mixture, ${ }^{21}$ or the related $\mathrm{iPrOH}, \mathrm{EtOH}, \mathrm{BuOH}$ mixture. ${ }^{22}$ The copper catalyzed alkylation of acetone with $\mathrm{BuOH}^{23}$ and the catalytic dehydration of ABE mixture over $\gamma$-alumina catalyst show the versatility of this chemical platform. ${ }^{24}$ For instance, Lee and coworkers have used $\mathrm{Pd} @ \mathrm{C}$ with $\mathrm{CaO}$ as a solid base for the conversion of $\mathrm{ABE}$ mixture in a batch reactor at $180{ }^{\circ} \mathrm{C}$ without any added solvent to obtain a mixture of ketones and their corresponding alcohols with $78 \%$ yield based on acetone. ${ }^{25}$ The mixture was further converted one-pot to the corresponding alkane mixture using 34.5 bar $\mathrm{H}_{2}$ at $270{ }^{\circ} \mathrm{C}$, with $74.7 \%$ overall yield based on acetone. Onyestyák and co-workers designed a flow reactor containing two separated beds for the consecutive

Received: February 12, 2018

Revised: April 16, 2018

Published: May 30, 2018 
Scheme 1. Key Reaction Steps and Main Side Reactions in the Catalytic Conversion of 1-Butanol and Acetone to C7 and C11 Ketones

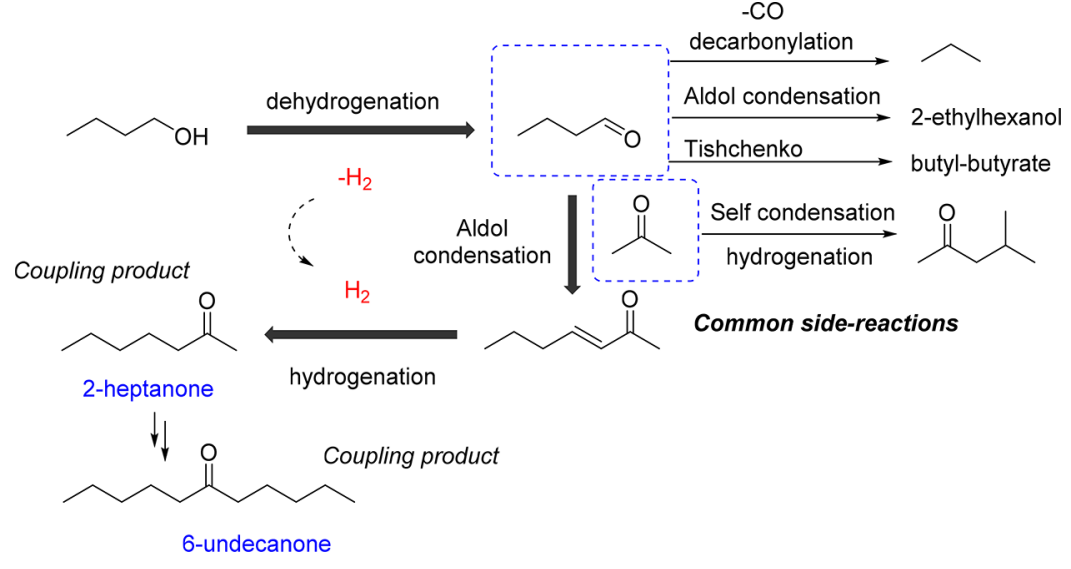

coupling and hydrodeoxygenation sequence to produce $\mathrm{C} 5-\mathrm{C} 7$ alkanes from ethanol-acetone mixture. ${ }^{26} \mathrm{Tan}$, Shen and coworkers have introduced a $\mathrm{Ni}-\mathrm{MgO}-\mathrm{SiO}_{2}$ catalyst with improved water resistance for the highly selective conversion of solventless $\mathrm{ABE}$ mixtures to $\mathrm{C} 5-\mathrm{C} 15$ ketones and alcohols at $240^{\circ} \mathrm{C} .{ }^{27}$

Herein we describe a simple catalyst system consisting of $\mathrm{Mg}-$ $\mathrm{Al}-\mathrm{PMO}$ and Raney nickel, for the very efficient coupling of acetone and 1-butanol ${ }^{28}$ as well as the selective coupling of $\mathrm{ABE}$ mixture to long chain ketones at $200{ }^{\circ} \mathrm{C}$ and hydrogeoxygenation of these over non-noble-metal catalysts to the corresponding fuel range alkanes with excellent carbon balance.

\section{EXPERIMENTAL PROCEDURE}

Catalyst Preparation. The HTC (hydrotalcite) catalyst precursor was prepared by a coprecipitation method, according to literature procedures. $^{29-31}$ A solution containing $\mathrm{MgCl}_{2} \cdot 6 \mathrm{H}_{2} \mathrm{O}(0.15 \mathrm{~mol}$, $30.05 \mathrm{~g}), \mathrm{AlCl}_{3} \cdot 6 \mathrm{H}_{2} \mathrm{O}(0.05 \mathrm{~mol}, 12.07 \mathrm{~g})$ in deionized water $(0.2 \mathrm{~L})$ was slowly added to an aqueous solution $(0.2 \mathrm{~L})$ of $\mathrm{Na}_{2} \mathrm{CO}_{3}(0.05 \mathrm{~mol}$, $5.3 \mathrm{~g}$ ) at $60^{\circ} \mathrm{C}$ under vigorous stirring. The $\mathrm{pH}$ was carefully maintained between 9 and 10 by adjusting with frequent additions of an aqueous solution of $\mathrm{NaOH}(1 \mathrm{M})$. The mixture was vigorously stirred for $72 \mathrm{~h}$ at $60{ }^{\circ} \mathrm{C}$. After cooling to room temperature, the suspension was filtered, and the solid was washed with deionized water and resuspended into a solution of $\mathrm{Na}_{2} \mathrm{CO}_{3}(2 \mathrm{M})$, which was stirred for $24 \mathrm{~h}$ at $40^{\circ} \mathrm{C}$. After, the catalyst precursor was filtered and washed with deionized water until the washings were chloride-free (tested with $\mathrm{AgNO}_{3}$ solution). The solid was dried at $120^{\circ} \mathrm{C}$ overnight, and the hydrotalcite precursor (HTC) was obtained as a white powder $(14.7 \mathrm{~g})$. The corresponding porous metal oxide (PMO) was obtained after calcining a portion of the HTC material at $460{ }^{\circ} \mathrm{C}$ for $24 \mathrm{~h}$. Elemental analyses were performed on a PerkinElmer instrument (Optima 7000DV) after full solubilization of the PMO catalysts in diluted nitric acid.

The various doped hydrotalcites (Cu20PMO, Cu10Ni10PMO, $\mathrm{Cu} 10 \mathrm{Zn} 10 \mathrm{PMO}, \mathrm{Ni20PMO}$, Co20PMO) were prepared by replacing a portion of the $\mathrm{Mg}^{2+}$ ions with additional metal dopants, otherwise following the procedure above. In Cu20PMO, Ni20PMO and Co20PMO, $20 \mathrm{~mol} \%$ of the $\mathrm{Mg}^{2+}$ were replaced by the corresponding two valent metal ions $\mathrm{Cu}^{2+}, \mathrm{Ni}^{2+}$ and $\mathrm{Co}^{2+}$ respectively. In the $\mathrm{Cu} 10 \mathrm{Ni10PMO}$ and $\mathrm{Cu} 10 \mathrm{Zn} 10 \mathrm{PMO}, 10 \mathrm{~mol} \%$ of $\mathrm{Mg}^{2+}$ was replaced by $\mathrm{Cu}$ ions whereas $10 \mathrm{~mol} \%$ was replaced by $\mathrm{Ni}$ and $\mathrm{Zn}$, respectively. To demonstrate the successful incorporation of the two-valent transition metal ions, the composition of PMO catalysts was investigated by ICP analysis, which typically resulted in an elemental composition that closely matched the theoretical one (for a detailed description, see Supporting Information, Section 4.1 Table S15). In order to independently confirm the formation of hydrotalcite structures, powder XRD spectra for all HTCs and for the corresponding PMOs were recorded (see Supporting Information, Section 4.2 for details). Indeed, this analysis confirmed the formation of the envisioned hydrotalcite structures in all samples.

Representative Procedure of a Catalytic Coupling of Butanol with Acetone. First, $15 \mathrm{mg}$ of Raney nickel slurry was placed in a Swagelok stainless steel microreactor $(10 \mathrm{~mL})$ equipped with a Teflon coated magnetic stirring bar followed by a rapid addition of 1-butanol $(5.46 \mathrm{mmol}, 0.5 \mathrm{~mL})$, acetone $(2.7 \mathrm{mmol}, 0.2 \mathrm{~mL})$, and dodecane $(0.22$ mmol, $50 \mu \mathrm{L}$, internal standard). Next, $200 \mathrm{mg}$ of $\mathrm{Mg}-\mathrm{Al}-\mathrm{PMO}$ and heptane $(2 \times 1 \mathrm{~mL})$ solvent was added. The reactor was sealed and placed in an aluminum block preheated at the desired temperature. After the indicated reaction time, the microreactor was cooled down with an ice-water bath and subsequently carefully opened. The liquid sample as well as the catalysts were quantitatively transferred to a $15 \mathrm{~mL}$ centrifuge tube. Additional $\mathrm{MeOH}(2 \times 1 \mathrm{~mL})$ was used to wash the reactor and recover all catalyst residues. After centrifugation, the solution was transferred into a glass vial, washed four times with $2 \mathrm{~mL} \mathrm{MeOH}$ and analyzed by GC-FID (Hewlett-Packard 6890 series equipped with a HP5 capillary column) in order to determine the 1-butanol and acetone conversion and selectivity of the products. Compounds were also identified by GC-MS and the injection of pure reference standards for the comparison of retention times in the GC column.

For ABE mixture, acetone $(2.9 \mathrm{mmol}, 0.21 \mathrm{~mL})$, butanol $(4.6 \mathrm{mmol}$, $0.42 \mathrm{~mL})$, and ethanol $(1.2 \mathrm{mmol}, 70 \mu \mathrm{L})$ were used as substrate; otherwise, the procedure was identical. The ratio of A:B:E is kept at 2.3:3.7:1 molar ratio as expected from the mixture accessible directly from $\mathrm{ABE}$ fermentation.

Catalytic Hydrodeoxygenation of Long Chain Ketones to Alkanes. The mixture of chain elongated ketones obtained following the previous procedure, (or model compounds) in hexane $(\sim 10 \mathrm{~mL})$ were loaded into a $15 \mathrm{~mL}$ autoclave equipped with a magnetic stirring

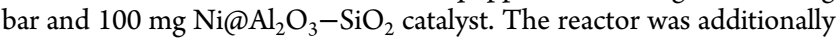
purged with $\mathrm{H}_{2}$ three times then pressurized to $40 \mathrm{bar}$, the autoclave was placed in a metal block preheated at $220^{\circ} \mathrm{C}$ and the reaction proceeded for $12 \mathrm{~h}$. After, the reactor was cooled down by compressed air and icewater bath, respectively. The content of the reactor was transferred to a $15 \mathrm{~mL}$ centrifuge tube and the reactor was washed with additional amounts $\left(5^{*} 0.5 \mathrm{~mL}\right)$ of cold hexane. The catalyst was separated by centrifugation, a sample from the liquid phase was injected to GC-MS and parallel to GC-FID and the carbon yield was calculated based on carbon number relatively to the intensity of the internal standard. More details on product analysis are given in the Supporting Information, Section 1.2 and 1.5 .

\section{RESULTS AND DISCUSSION}

Inspired by the above-described prior art and following our interest in the use of hydrotalcite derived doped porous metal oxides for the conversion of renewables involving hydrogenation $^{32}$ or hydrogen transfer processes, ${ }^{29,33}$ as well as diverse $\mathrm{C}-\mathrm{C}$ bond formation reactions including the Guerbet coupling 


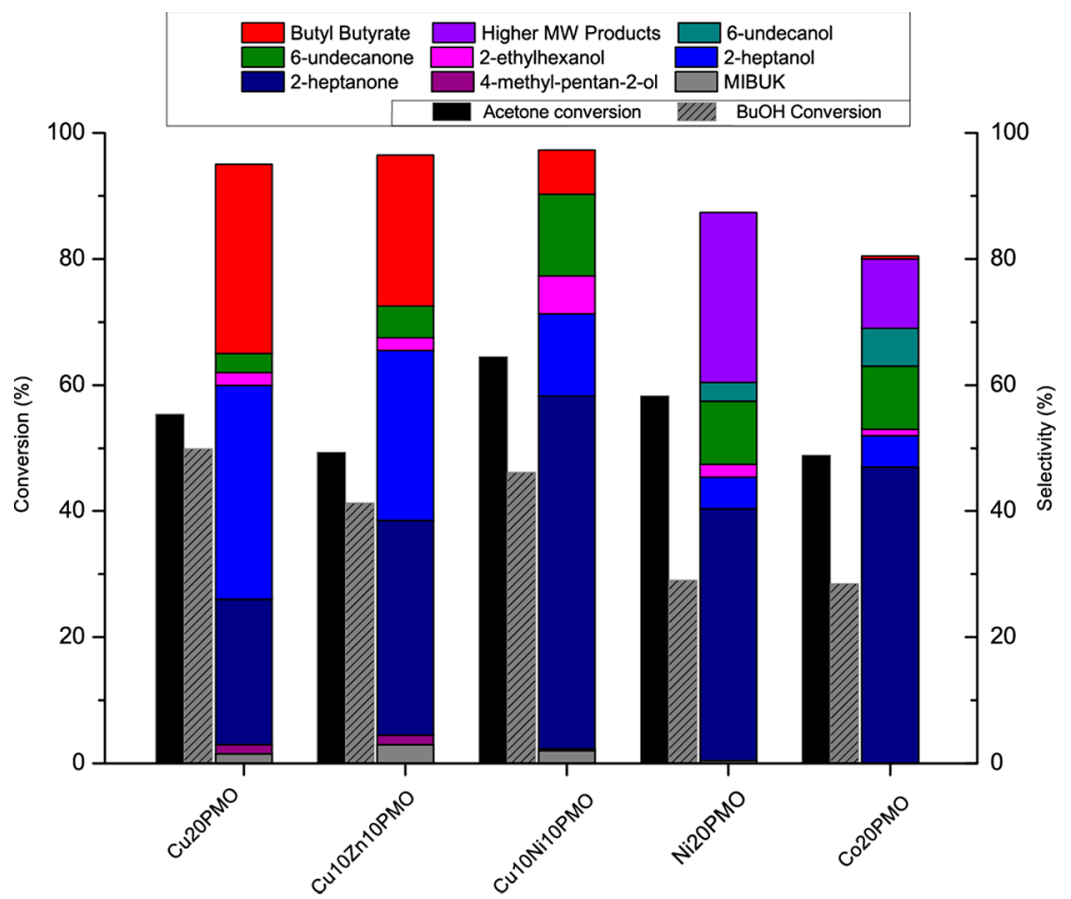

Figure 1. Screening of various PMO catalysts containing different metal dopants in the catalytic coupling of acetone with 1-butanol. Right: Acetone and 1-butanol conversion. Left: Product selectivity by GC-FID. Reaction conditions: $200 \mathrm{mg}$ catalyst, acetone $(2.70 \mathrm{mmol}, 0.2 \mathrm{~mL}), 1-\mathrm{BuOH}(5.46 \mathrm{mmol}$, $0.5 \mathrm{~mL})$, acetone-butanol molar ratio $1: 2$, heptane $\left(2.1 \mathrm{~mL}\right.$, solvent), dodecane $(0.22 \mathrm{mmol}, 50 \mu \mathrm{L}$, internal standard $), 20 \mathrm{~h}, 200^{\circ} \mathrm{C}$. For all data in table format, see the Supporting Information, Table S1.

of ethanol to butanol ${ }^{34}$ and the coupling of challenging alcohol mixtures with cyclopentanone, ${ }^{35}$ we set to design a simple, entirely noble-metal-free catalyst system for the transformation of $\mathrm{ABE}$ mixture to long chain ketones and subsequently to fuelrange alkanes. We have first focused our attention on finding an appropriate catalyst for the coupling of 1-butanol and acetone, two main components of the ABE mixture. As shown in Scheme 1 , the transformation of acetone and 1-butanol to long chain ketones requires efficient dehydrogenation of the primary alcohol, followed by a cross aldol condensation with acetone and subsequent hydrogenation of the double bond in the corresponding aldol condensation product. A number of side reactions, previously also identified by Toste ${ }^{18}$ and others, exist in this system, making the selective formation of 6-undecanone challenging.

First, we have selected a number of hydrotalcite derived solid bases, high surface area porous metal oxides (PMO) comprising various dopants $(\mathrm{Cu}, \mathrm{Ni}, \mathrm{Zn}, \mathrm{Co})$, as starting point for our investigation (Figure 1, Table S1). We expected that the nature of the dopant will influence reactivity since in our earlier study on the Guerbet reaction we observed significant differences in the extent of dehydrogenation, aldol condensation as well as the Tishchenko pathway, depending on the PMO composition. Gratifyingly, there was considerable conversion of both acetone and 1-butanol with all PMO catalyst tested, and a significant amount of the one side coupling product 2-heptanone together with the corresponding alcohol 2-heptanol. Indeed, with diverse metal dopants, the extent of side reactions appeared different. As expected from earlier studies, $\mathrm{Cu} 20 \mathrm{PMO}$ exhibited significant amounts of butyl-butyrate and a similar behavior was observed with Cu10Zn10PMO (Table S1, entries 1 and 2). A related behavior was observed by Goulas et. al who reported a significant esterification side reaction with HTC supported $\mathrm{Cu}$ catalyst prepared by impregnation. ${ }^{20}$ Interestingly, the Cu10Ni10PMO containing the same amount of $\mathrm{Cu}$ dopant, but $\mathrm{Ni}$ instead of $\mathrm{Zn}$ resulted in much less butyl butyrate (7\%) and higher amount $(56 \%)$ of 2-heptanone as well as (13\%) long chain ketone 6undecanone (Table S1, entry 3 ). The PMO containing Ni or Co both resulted in very similar substrate conversion values, up to $\sim 60 \%$ ketones and more significant amount of higher $\mathrm{Mw}$ products (Table S1, entries 4 and 5). Although among these catalysts the best results were achieved with the Cu10Ni10PMO and the conversion values and low selectivity to the double coupling products were not yet satisfactory.

A very high selectivity to $(\mathrm{C} 7-\mathrm{C} 11)$ ketones was described by Goulas et. al reporting the beneficial use of a CuPd bimetallic catalyst prepared by incipient wetness impregnation on a commercially available HTC catalysts. ${ }^{18}$ The group has identified decarbonylation as one of the major source of side reactions, catalyzed by the Pd contained in the catalysts. Because the $\mathrm{Cu}$ containing catalysts were giving significant Tishchenko activity, and none of the doped PMO tested gave sufficient conversion levels, we turned our attention to the use of simple $\mathrm{Mg}-\mathrm{Al}-$ PMO obtained directly by calcination of a typical hydrotalcite that is known to efficiently catalyze aldol condensation processes. $^{36}$ Furthermore, instead of Pd we have selected Raney nickel that is a highly efficient transfer hydrogenation catalyst, but is expected to have less decarbonylation activity. Very recently, Zhang and co-workers have shown that cyclopentanol can be converted to $\mathrm{C} 10$ and $\mathrm{C} 15$ oxygenates in the presence of Raney $\mathrm{Ni}$ and a $\mathrm{PMO}$ with a different $\mathrm{Mg} / \mathrm{Al}$ ratio (2:1 compared to $3: 1$ in our case).$^{37}$

Combination of Raney Nickel and PMO for Increased Activity. Gratifyingly, when we have attempted the coupling reaction between acetone and 1-butanol in the presence of $15 \mathrm{mg}$ Raney $\mathrm{Ni}$ and $200 \mathrm{mg} \mathrm{Mg}-\mathrm{Al}-\mathrm{PMO}$, excellent results were obtained (Figure 2, Table S2, Entry 1). Almost full substrate conversion was seen alongside high selectivity (61.5\%) of 6- 


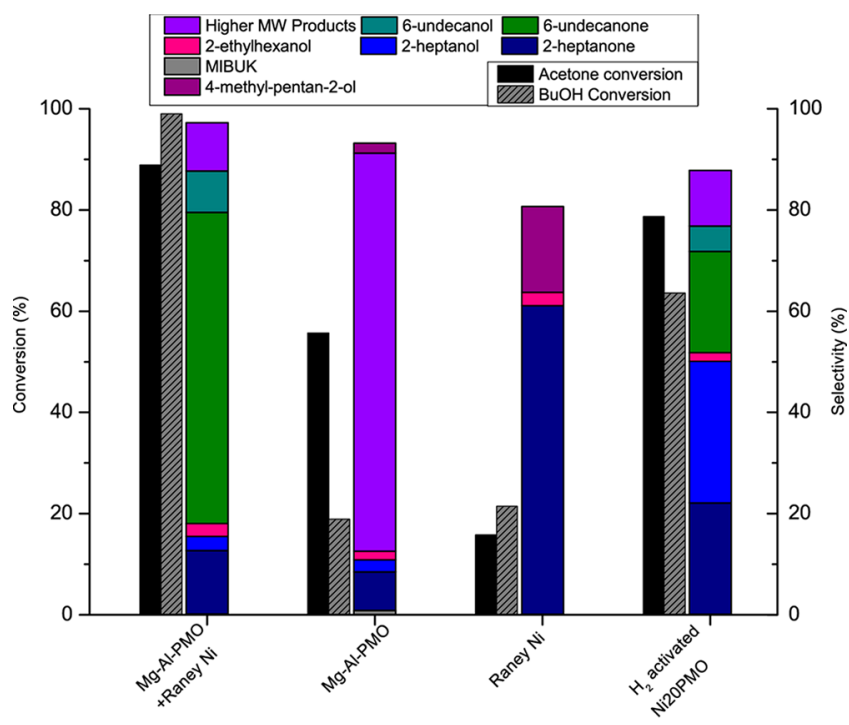

Figure 2. Evaluating various $\mathrm{Ni}$ containing catalyst in the catalytic coupling of acetone with 1-butanol. Left: Acetone and 1-butanol conversion. Right: Product selectivity by GC-FID. Reaction conditions: $200 \mathrm{mg}$ catalyst, acetone $(2.70 \mathrm{mmol}, 0.2 \mathrm{~mL}), 1-\mathrm{BuOH}(5.46 \mathrm{mmol}, 0.5$ $\mathrm{mL})$, acetone-butanol molar ratio $1: 2$, heptane $(2.1 \mathrm{~mL}$, solvent), dodecane $\left(0.22 \mathrm{mmol}, 50 \mu \mathrm{L}\right.$, internal standard), $20 \mathrm{~h}, 200{ }^{\circ} \mathrm{C}$. For all data in table format, see the Supporting Information, Table S2.

undecanone and the combined selectivity for C7 and C11 ketones and alcohols as desired chain elongated products was over $86 \%$. In terms of side reactions, a small amount of higher molecular weight side products were detected, but no butylbutyrate was formed. The superior activity of this catalyst can be explained by the fact that Raney $\mathrm{Ni}$ is a more efficient dehydrogenation and hydrogenation catalyst, compared to the various metal dopants in the PMO previously tested, present in their oxide form. When the $\mathrm{Mg}-\mathrm{Al}-\mathrm{PMO}$ was used alone, the color of the reaction mixture turned orange and the formation of higher $\mathrm{M}_{\mathrm{W}}$ products, originating from acetone self-condensation were largely predominant, as expected. On the other hand, when only Raney Ni was used, low substrate conversion was seen and a small quantity of 2-heptanone was found. Interestingly, also 4,4dibutoxybutane was detectable that likely originates from the acetalization of the butanal intermediate formed upon dehydrogenation, a pathway apparently more dominant in the absence of aldol condensation, supporting the major role of Raney $\mathrm{Ni}$ in catalyzing dehydrogenation. This mixture of catalysts was investigated by TEM measurement, combined with EDX. As expected, the phase boundaries of the physical mixture were clearly observable even after reaction (for description, see the Supporting Information, Section 4.3). Interestingly, when the Ni20PMO was first preactivated at 500 ${ }^{\circ} \mathrm{C}$ in hydrogen atmosphere and was evaluated in the reaction after preactivation, the amount of 6-undecanone increased. This hints at the fact, that $\mathrm{Ni}(0)$ together with a basic porous metal oxide, are essential for good activity. Related $\mathrm{Ni}-\mathrm{Al}$ hydrotalcite derived catalysts are known for $\mathrm{CO}_{2}$ methanation and $\mathrm{Ni}-\mathrm{Mg}-$ $\mathrm{Al}$ hydrotalcite derived catalysts for ammonia decomposition. $^{38-41}$ For all these systems, the formation of differentsized $\mathrm{Ni}$ nanoparticles was observed upon activation in $\mathrm{H}_{2}$ stream. It was previously reported that $\mathrm{Ni}$ nanoparticles, which were well isolated and immobilized in the porous metal oxide matrix displayed higher thermostability, while also being easily accessible to the reactants. ${ }^{40}$
In our hands, the freshly prepared, not activated Ni20PMO revealed homogeneously distributed nickel and a porous structure as evidenced by TEM and EDX analyzis (Figure S13). Upon activation at $500{ }^{\circ} \mathrm{C}$ in $\mathrm{H}_{2}$ flow, formation of particles was visible by TEM analysis; however, their sizes were too small $(1-4 \mathrm{~nm})$ to discriminate them from the matrix by elemental mapping (Figure S14). Therefore, from the same batch of porous metal oxide precursor, we prepared a new batch of activated catalyst at $600^{\circ} \mathrm{C}$ in $\mathrm{H}_{2}$ flow. Indeed, in this case the formation of larger, Ni-rich particles $(7-11 \mathrm{~nm})$ was observed (Figures S15 and S19).

The catalyst, which was activated at $600{ }^{\circ} \mathrm{C}$, showed slightly better conversion and similarly good selectivity toward the chain elongated products (Table S2, entry 5).

Next, both Ni-PMO (activated at 500 and $600{ }^{\circ} \mathrm{C}$, respectively) were analyzed by TEM and EDX after reaction (Figure S18 vs S19).

The flexible incorporation of $\mathrm{Ni}$ into the PMO structure synthetically, will open possibilities for potential future finetuning of catalyst composition and preparation methods, because the amount of $\mathrm{Ni}$ in the PMO during coprecipitation method can be carefully adjusted.

Effect of Various Reaction Parameters. Next, we conducted a series of experiments by gradually increasing the substrate amounts by maintaining the total volume of $2.8 \mathrm{~mL}$ of the reaction mixture (Figure 3, Table S3). Experiments were

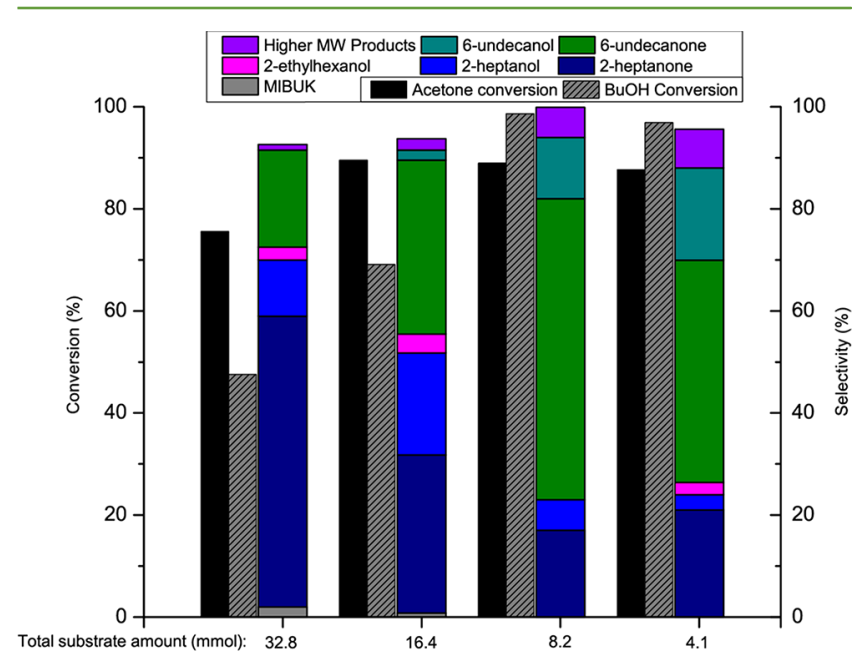

Figure 3. Evaluating the effect of increasing substrate loading in the catalytic coupling of acetone with 1-butanol. Left: Acetone and 1butanol conversion. Right: Product selectivity by GC-FID. Reaction conditions: $200 \mathrm{mg} \mathrm{Mg}-\mathrm{Al}-\mathrm{PMO}$ and $15 \mathrm{mg}$ Raney Ni catalyst, acetone-butanol molar ratio $1: 2$, dodecane $(0.22 \mathrm{mmol}, 50 \mu \mathrm{L}$, internal standard), $20 \mathrm{~h}, 200^{\circ} \mathrm{C}$. For all data in table format, see the Supporting Information, Table S3.

conducted between 4.1 and $32.8 \mathrm{mmol}$ total substrate loading. Interestingly, though the acetone conversion did not significantly change, the 1-butanol conversion and 6-undecanone selectivity gradually decreased with an increasing amount of substrate loading. Gratifyingly, the neat conditions and relatively high substrate loading also resulted in an excellent selectivity for C7C11 ketones and alcohols (combined 86.3\%), albeit with lower conversion values.

In the next experiments, the acetone to butanol ratio was varied as 1.9, 2.0, 2.1 (Figure S1 and Table S4). The 1:2 acetone to butanol ratio resulted in the highest amount of double 
Scheme 2. Proposed Reaction Network during Transformation of 1-Butanol and Acetone to 2-Heptanone and 6-Undecanone ${ }^{a}$

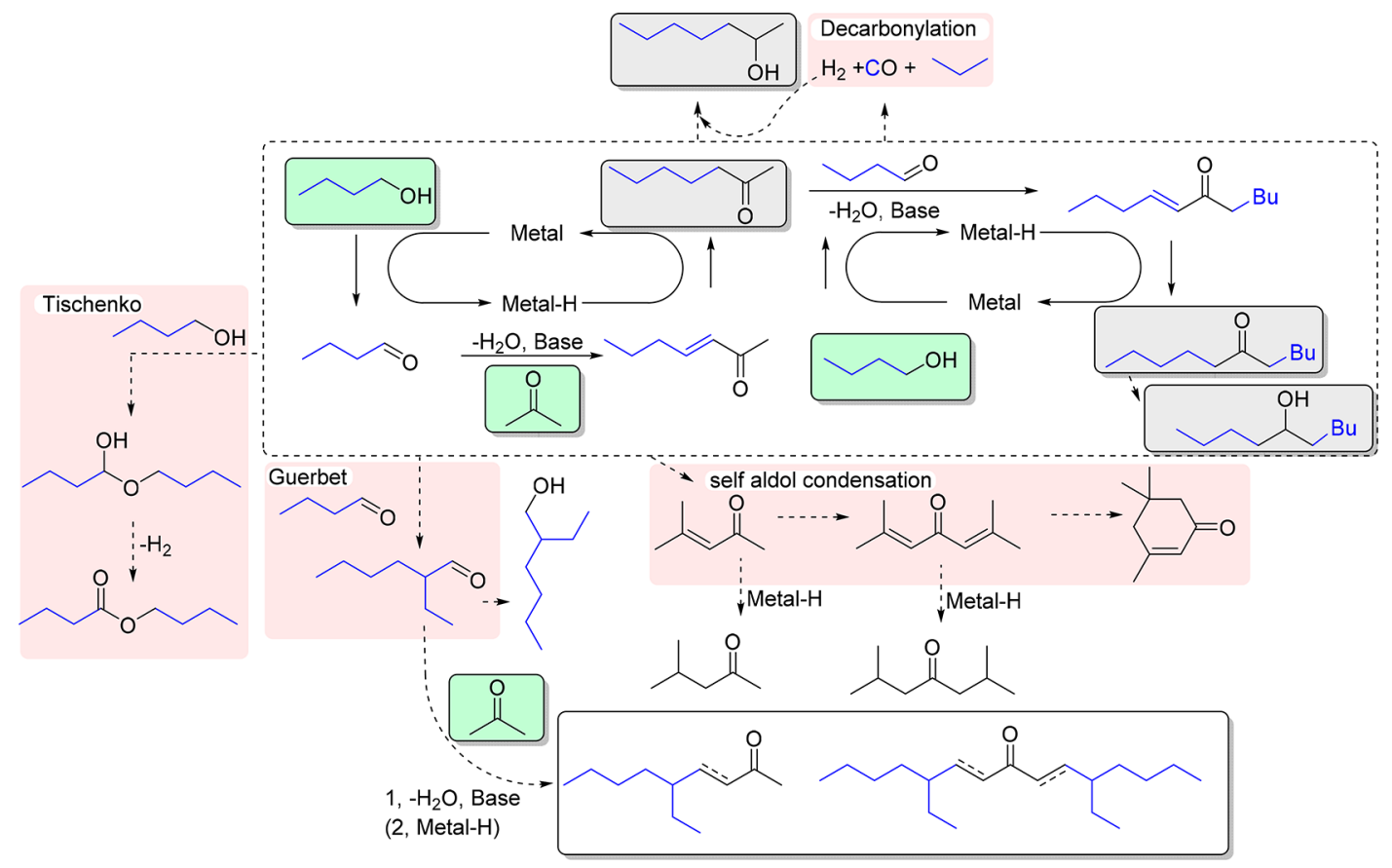

${ }^{a}$ Highlighted fields: Substrates (green), desired products (grey), undesired pathways (red).

alkylated C11 ketones and alcohols (combined 73\%). Next, the reaction was conducted at $180-220{ }^{\circ} \mathrm{C}$ reaction temperatures (Figure S2, Table S5) without significant variation in results. The reproducibility of the system was also verified by running 3 parallel experiments (Figure S3 and Table S6), resulting in a negligible variation, within $60.5-62 \%$ of 6 -undecanone selectivity.

Mechanistic Considerations. Although the primary reaction pathways (Scheme 1) en route to 2-heptanone and 6undecanone, involving 1-butanol dehydrogenation, aldol condensation with acetone (or 2-heptanone) and hydrogenation appear straightforward, this transformation is complicated by a number of side reactions. The full proposed reaction network is depicted on Scheme 2, which can be used to explain the product profiles that were obtained during catalyst screening, and even the differences between the catalysts tested.

We found that the Raney Ni/PMO catalyst system leads to excellent substrate conversions and good selectivity of the desired products, resulting in minimal side reactions such as the formation of butyl-butyrate or acetone-self-condensation and related products. The latter process was the major pathway when PMO was used without any metal catalyst that promotes alcohol dehydrogenation (Table S2). We were further interested in other specific side reactions, such as, for example the origin of the long branched ketones (Scheme 2). These should originate from the coupling of 2-ethyl-hexanol, the product of the Guerbet reaction of 1-butanol, with acetone. In order to clarify this, a separate experiment was conducted using acetone and 2-ethyhexanol (Figure S4, Table S9) confirming the formation of higher alkylation products. An interesting question is the presence of 2heptanol and 6-undecanol in addition to the desired ketones, as also observed by Goulas et al. ${ }^{20}$ Though their presence is not problematic given the next reaction step being a hydrodeoxygenation to alkanes, their formation indicates that an extra equivalent of hydrogen is produced in the system. One source of this is the Tishchenko pathway, the dehydrogenation of the hemiacetal to form butyl-butyrate. Another possible source of the hydrogen may be the decarbonylation reaction, which results in only gaseous products: carbon-monoxide and propane from butanal. Gas phase analysis of a typical reaction, using GC-TCD was performed, confirming the presence of propane as well as $\mathrm{CO}$ in addition to hydrogen (for description, see the Supporting Information, Section 2.1.2).

Product Formation Profiles and Hydrodeoxygenation. To investigate the capacity of our system, we have conducted experiments from 1.25 to $10 \mathrm{~h}$ at $200{ }^{\circ} \mathrm{C}$ under optimized conditions (Figure 4, Table S7). To our delight, already after 1.25 $\mathrm{h}$, the acetone and butanol conversion reached $79.4 \%$ and $63.1 \%$, respectively and already a considerable amount of $\mathrm{C} 11$ products were formed. Interestingly already after $2.5 \mathrm{~h}$, the reaction was almost complete with $93 \%$ of acetone conversion (calculated $4656 \mu \mathrm{mol} \cdot \mathrm{g} \mathrm{cat}^{-1} \cdot \mathrm{h}^{-1}$ ) and a total $87 \%$ selectivity to chain elongated products was obtained, from which $71 \%$ were ketones (58\% C7+ ketones) and 16\% alcohols (9.6\% C7+ alcohols). The combined selectivity to $\mathrm{C} 11$ alcohols and ketones combined was as high as $64.7 \%$. Over $20 \mathrm{~h}$, the amount of alcohols obtained from the ketone products slightly increased and the total $\mathrm{C} 7+$ oxygenates were slightly increased from $67 \%$ to $71 \%$.

Next, we have performed the hydrodeoxygenation (HDO) of the obtained mixtures in order to obtain clean mixtures of alkanes. To this end, the commercially available $\mathrm{Ni} / \mathrm{SiO}_{2}-\mathrm{Al}_{2} \mathrm{O}_{3}$ catalyst ${ }^{42}$ was selected at $220^{\circ} \mathrm{C}$ with $40 \mathrm{bar}_{2}$ and $12 \mathrm{~h}$ reaction time. These reaction conditions have been found through optimization using 2-heptanone as a model compound. Upon $\mathrm{HDO}$, the carbon yield of the product mixture was carefully examined, indeed showing very good results (Figure 5, Table 1, Figure S7). Already after $2.5 \mathrm{~h}$, the amount of $\mathrm{C} 11$ alkanes was significant $(212.2 \mathrm{mg})$ and excellent carbon yield were obtained (78.4\%). All the carbon yields are calculated based on the carbon content of the initial $\mathbf{A B}$ and $\mathbf{A B E}$ mixture (Section S3.2.1). The slight loss of mass balance is attributed to two factors, first to the loss of carbon-containing gases via decarbonylation in the first 


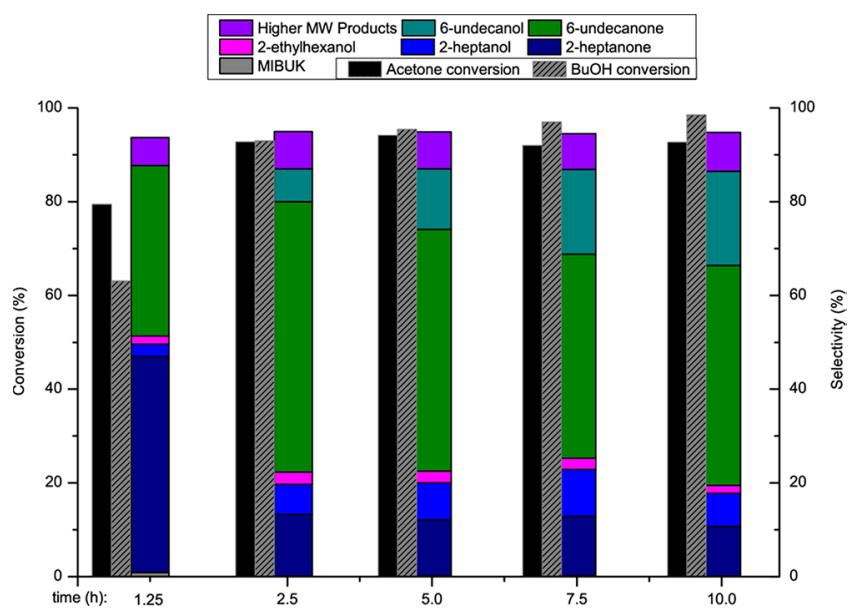

Figure 4. Product formation profiles in the catalytic coupling of acetone with 1-butanol for $10 \mathrm{~h}$. Left: Acetone and 1-butanol conversion. Right: Product selectivity by GC-FID. Reaction conditions: $200 \mathrm{mg} \mathrm{Mg}-\mathrm{Al}-$ PMO and $15 \mathrm{mg}$ Raney Ni catalysts, acetone $(2.70 \mathrm{mmol}, 0.2 \mathrm{~mL}), 1$ $\mathrm{BuOH}(5.46 \mathrm{mmol}, 0.5 \mathrm{~mL})$, acetone-butanol molar ratio 1:2, hexane ( $2.1 \mathrm{~mL}$, solvent), dodecane $(0.22 \mathrm{mmol}, 50 \mu \mathrm{L}$, internal standard $), 200$ ${ }^{\circ} \mathrm{C}$. For all data in table format, see the Supporting Information, Table S7.

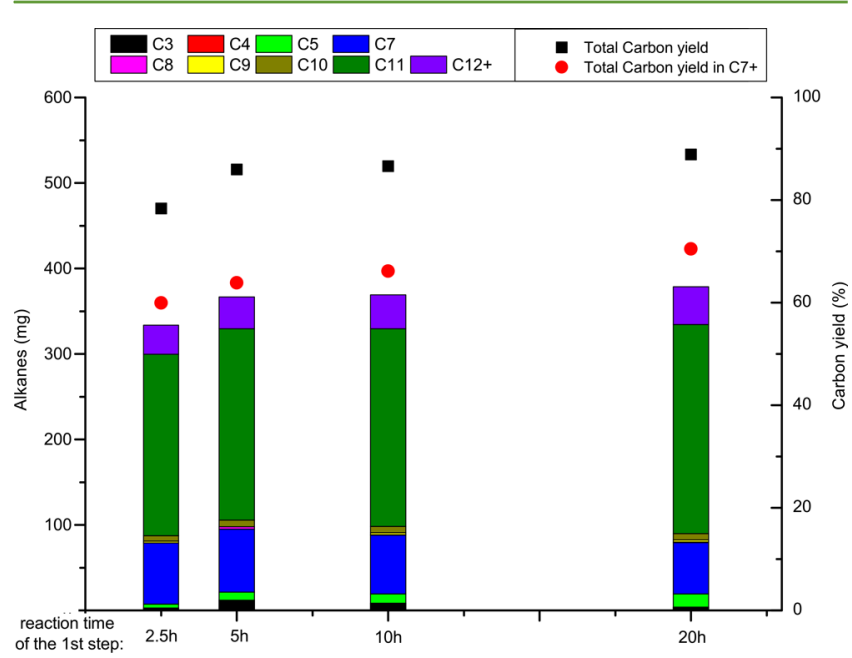

Figure 5. Results of the catalytic HDO of product mixtures obtained upon catalytic coupling of acetone with 1-butanol for different reaction times. Left: Weight of alkanes obtained based on chain length. Right:

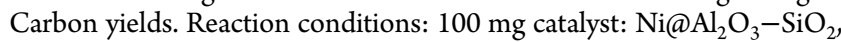
dodecane $\left(0.22 \mathrm{mmol}, 50 \mu \mathrm{L}\right.$, internal standard), $220{ }^{\circ} \mathrm{C}$. Values determined by FID, using internal standard. For all data in table format, see the Supporting Information, Table 1 and Table S12.

coupling step (see the Supporting Information, Section 2.1.2) and second the leftover acetone in the product mixture prior to HDO was transformed to volatile propane (Table S10, Figure 5).
The $\mathrm{Ni} / \mathrm{SiO}_{2}-\mathrm{Al}_{2} \mathrm{O}_{3}$ catalyst was also used in our earlier work for the HDO of lignocellulose derived product mixtures at 250 ${ }^{\circ} \mathrm{C}$. It displayed excellent robustness and recyclability without coking in the HDO of model compound 4-propylcyclohexanone for 20 consecutive cycles, converting $12.4 \mathrm{~g}$ ( $88.5 \mathrm{mmol})$ substrate with just $200 \mathrm{mg}$ catalyst. ${ }^{35}$ Therefore, we postulate that this catalyst will be highly suitable for a continuous flow setup involving $\mathrm{HDO}$ of products originating from the coupling of $\mathrm{ABE}$ mixtures.

Coupling of ABE Mixture and Hydrodeoxygenation. Under the conditions found ideal for the $A B$ mixture, we have explored the catalytic coupling of the $\mathrm{ABE}$ mixture at $200{ }^{\circ} \mathrm{C}$ (Figure 6, Table S8). The molar ratio of the substrates was kept (2.3:3.7:1), mimicking the real fermentation mixture. Gratifyingly, full 1-butanol and ethanol conversion and $87.3 \%$ acetone conversion was seen after $20 \mathrm{~h}\left(581 \mu \mathrm{mol} \cdot \mathrm{g} \mathrm{cat}^{-1} \cdot \mathrm{h}^{-1}\right)$ and an excellent $88.4 \%$ selectivity toward oxygenates was achieved. There oxygenates comprised ketones $(77.4 \%$, out of which $57.6 \%$ were $\mathrm{C} 7+$ ketones) and a smaller amount of alcohols (11\% out of which $7.5 \%$ were $\mathrm{C} 7+$ alcohols). Moreover, the extent of side reactions was minimal, since only $9.6 \%$ of high molecular weight side products and $0.2 \%$ MIBUK were obtained.

Next, catalytic HDO of this mixture was performed and the carbon yields of alkanes (Figure S8.) were calculated based on an internal standard. According to this, an excellent $84 \%$ total carbon yield was achieved (Table 2, Table S13). The carbon yield of $\mathrm{C} 7+$ alkanes was found to be slightly lower compared to the value seen with the $\mathrm{AB}$ mixture, because acetone mono or dialkylation with $\mathrm{EtOH}$ yields $\mathrm{C} 5-\mathrm{C} 7$ ketones respectively, which do not contribute to the $\mathrm{C} 7+$ region after $\mathrm{HDO}$.

\section{CONCLUSIONS}

Here we describe that the solid base $\mathrm{Mg}-\mathrm{Al}-\mathrm{PMO}$ in combination with small amount of Raney $\mathrm{Ni}$ provides high selectivity in the coupling of 1-butanol with acetone as well as $\mathrm{ABE}$ mixture to longer chain ketones. The extent of common side reactions such as ester formation and decarbonylation could be minimized. Notably, this catalyst system provides high selectivity to chain elongated ketones (73\%) and alcohols (12\%) as well as a total $\mathrm{C} 7+$ ketones $(62 \%)$ and alcohols (9.1\%) in the coupling of acetone and 1-butanol at $200{ }^{\circ} \mathrm{C}$ and it functions comparably well at $180{ }^{\circ} \mathrm{C}$. The observation that a $20 \% \mathrm{Ni}$ doped PMO, preactivated in $\mathrm{H}_{2}$ stream provides higher activity and selectivity toward $\mathrm{C} 7+$ oxygenated than simple Ni20PMO, suggests that novel catalyst systems could be easily prepared and examined with careful variation of the $\mathrm{Ni}, \mathrm{Mg}$, and $\mathrm{Al}$ ratios and the addition of other dopants can be investigated to further tailor catalyst performance. In Ni20PMO, the formation of $\mathrm{Ni}$ nanoparticles upon activation in $\mathrm{H}_{2}$ flow was confirmed by TEM analysis and EDX elemental mapping. Last, a simple hydrodeoxygenation protocol was established that enables the conversion of these mixtures into obtain fuel range alkanes with excellent carbon utilization (up to $89 \%$ ).

Table 1. Weight and Carbon Yield of Alkanes Obtained from the HDO of Catalytic Coupling Mixtures from Acetone and 1-Butanol

\begin{tabular}{|c|c|c|c|c|c|c|c|c|c|c|c|c|}
\hline \multirow[b]{2}{*}{ Reaction Time (h) } & \multicolumn{10}{|c|}{ Alkane Weight (mg) } & \multicolumn{2}{|c|}{ Carbon Yield (\%) } \\
\hline & $\mathrm{C} 3$ & $\mathrm{C} 4$ & $\mathrm{C} 5$ & $\mathrm{C} 7$ & $\mathrm{C} 8$ & $\mathrm{C} 9$ & $\mathrm{C} 10$ & C11 & $\mathrm{C} 12+$ & Total Alkanes & Total & $\mathrm{C} 7+$ \\
\hline 2.5 & 2.3 & 0.5 & 4.7 & 71.5 & 0 & 2.2 & 6.2 & 212.2 & 34.2 & 333.8 & 78.4 & 60.0 \\
\hline 5 & 11.9 & 0 & 9.7 & 73.6 & 2.7 & 0 & 7.7 & 223.9 & 37.2 & 366.5 & 86.0 & 63.9 \\
\hline 10 & 8.3 & 0 & 9.0 & 68.7 & 0.4 & 2.6 & 7.1 & 231.1 & 39.9 & 369.2 & 86.6 & 66.2 \\
\hline 20 & 3.4 & 0.7 & 15.2 & 60.0 & 0.8 & 2.4 & 7.5 & 244.7 & 44.1 & 378.7 & 88.9 & 70.5 \\
\hline
\end{tabular}




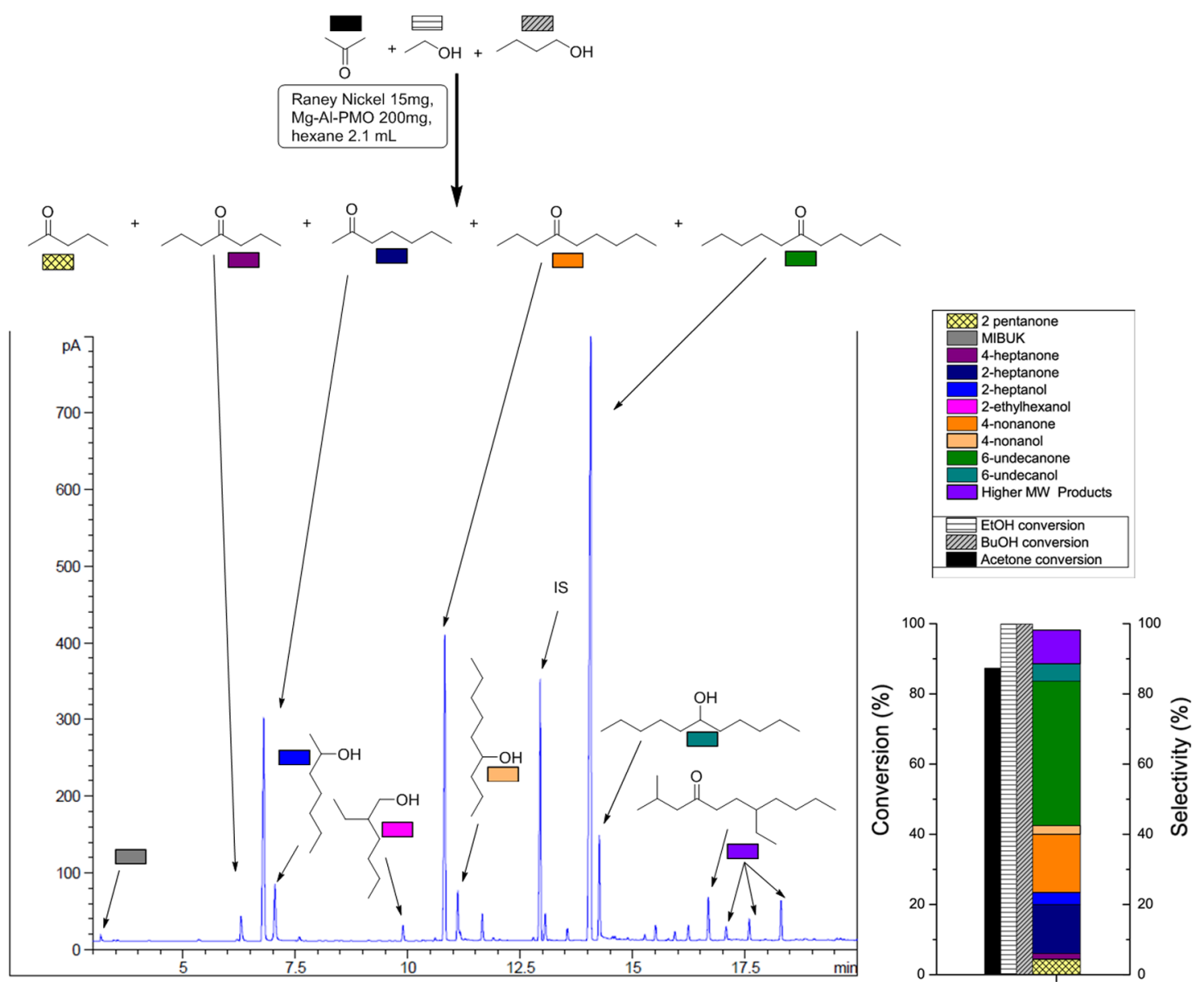

Figure 6. Results of the catalytic coupling of ABE mixture. Left: GC-FID trace of the product mixture showing all main components. Right: Product selectivities. Reaction conditions: $100 \mathrm{mg}$ cat: $\mathrm{Ni} @ \mathrm{Al}_{2} \mathrm{O}_{3}-\mathrm{SiO}_{2}$, dodecane $(0.22 \mathrm{mmol}, 50 \mu \mathrm{L}$, internal standard $), 220^{\circ} \mathrm{C}$. Values determined by FID, using internal standard. For all data in table format, see the Supporting Information, Table S8.

Table 2. Weight and Carbon Yield of Alkanes Obtained from the HDO of Catalytic Coupling Mixtures from Acetone, Ethanol, and 1-Butanol

\begin{tabular}{|c|c|c|c|c|c|c|c|c|c|c|c|c|}
\hline \multirow[b]{2}{*}{ Reaction Time (h) } & \multicolumn{10}{|c|}{ Alkane Weight (mg) } & \multicolumn{2}{|c|}{ Carbon Yield (\%) } \\
\hline & $\mathrm{C} 3$ & $\mathrm{C} 4$ & $\mathrm{C} 5$ & $\mathrm{C} 7$ & $\mathrm{C} 8$ & C9 & $\mathrm{C} 10$ & $\mathrm{C} 11$ & $\mathrm{C} 12+$ & Total Alkanes & Total & $\mathrm{C} 7+$ \\
\hline 20 & 3.4 & 0.6 & 22.9 & 68.5 & 3.4 & 62.7 & 6.3 & 152.7 & 30.5 & 351.0 & 84.0 & 61.3 \\
\hline
\end{tabular}

\section{ASSOCIATED CONTENT}

\section{S Supporting Information}

The Supporting Information is available free of charge on the ACS Publications website at DOI: 10.1021/acssuschemeng.8b00733.

Additional details regarding the materials, experimental procedures, characterization of catalysts, analysis of products and calculations (PDF)

\section{AUTHOR INFORMATION}

\section{Corresponding Author}

*K. Barta. Email: k.barta@rug.nl.

\section{ORCID}

Marc C. A. Stuart: 0000-0003-0667-6338

Katalin Barta: 0000-0002-8046-4248

\section{Notes}

The authors declare no competing financial interest.

\section{ACKNOWLEDGMENTS}

K.B. is grateful for financial support from the European Research Council, ERC Starting Grant 2015 (CatASus) 638076. This work is part of the research program Talent Scheme (Vidi) with project number 723.015 .005 (K.B.), which is partly financed by The Netherlands Organisation for Scientific Research (NWO). B.F. is grateful for the financial support from the Hungarian Ministry of Human Capacities (NTP-NFTÖ-17-B-0593). The authors are grateful to Léon Rohrbach for helping with the analysis of the gas phase of the reaction and to Zhuohua Sun for helping with the XRD measurements.

\section{REFERENCES}

(1) Horváth, I. T. Introduction: Sustainable Chemistry. Chem. Rev. 2018, 118, 369-371.

(2) Cséfalvay, E.; Akien, G. R.; Qi, L.; Horváth, I. T. Definition and application of ethanol equivalent: sustainability performance metrics for biomass conversion to carbon-based fuels and chemicals. Catal. Today 2015, 239, 50-55. 
(3) Horváth, I. T.; Mehdi, H.; Fábos, V.; Boda, L.; Mika, L. T. $\gamma$ Valerolactone-a sustainable liquid for energy and carbon-based chemicals. Green Chem. 2008, 10, 238-242.

(4) Alonso, D. M.; Bond, J. Q.; Dumesic, J. A. Catalytic conversion of biomass to biofuels. Green Chem. 2010, 12, 1493-1513.

(5) Deuss, P. J.; Barta, K.; de Vries, J. G. Homogeneous Catalysis for the Conversion of Biomass and Biomass-Derived Platform Chemicals. Catal. Sci. Technol. 2014, 4, 1174-1196.

(6) Sutton, A. D.; Waldie, F. D.; Wu, R.; Schlaf, M.; 'Pete' Silks, L. A.; Gordon, J. C. The hydrodeoxygenation of bioderived furans into alkanes. Nat. Chem. 2013, 5, 544-544.

(7) Wu, L.; Moteki, T.; Gokhale, A. A.; Flaherty, D. W.; Toste, D. F. Production of Fuels and Chemicals from Biomass: Condensation Reactions and Beyond. Chem 2016, 1, 32-58.

(8) Zaccheria, F.; Scotti, N.; Ravasio, N. The role of Copper in the upgrading of Bio-alcohols. ChemCatChem 2018, 10, 1526-1535.

(9) McGovern, P. E.; Zhang, J.; Tang, J.; Zhang, Z.; Hall, G. R.; Moreau, R. A.; Nuñez, A.; Butrym, E. D.; Richards, M. P.; Wang, C. S.; Cheng, G.; Zhao, Z.; Wang, C. Fermented beverages of pre-and protohistoric China. Proc. Natl. Acad. Sci. U. S. A. 2004, 101, 17593-17598.

(10) Lynd, L. R.; Weimer, P.J.; van Zyl, W. H.; Pretorius, I. S. Microbial cellulose utilization: fundamentals and biotechnology. Microbiol Mol. Biol. Rev. 2002, 66, 506-577.

(11) Sun, Y.; Cheng, J. Hydrolysis of lignocellulosic materials for ethanol production: a review. Bioresour. Technol. 2002, 83, 1-11.

(12) Goldemberg, J. Ethanol for a sustainable energy future. Science 2007, 315, 808-810.

(13) William Bunch, A. How Biotechnology Helped Maintain the Supply of Acetone for the Manufacture of Cordite During World War I. International Journal for the History of Engineering \& Technology 2014, 84, 211-226.

(14) Kumar, M.; Goyal, Y.; Sarkar, A.; Gayen, K. Comparative Economic Assessment of ABE Fermentation Based on Cellulosic and Non-Cellulosic Feedstocks. Appl. Appl. Energy 2012, 93, 193-204.

(15) Bankar, S. B.; Survase, S. A.; Ojamo, H.; Granström, T. The two stage immobilized column reactor with an integrated solvent recovery module for enhanced ABE production. Bioresour. Technol. 2013, 140, 269-276.

(16) Anbarasan, P.; Baer, Z. C.; Sreekumar, S.; Gross, E.; Binder, J. B.; Blanch, H. W.; Clark, D. S.; Toste, F. D. Integration of Chemical Catalysis with Extractive Fermentation to Produce Fuels. Nature 2012, 491, 235-239.

(17) Sreekumar, S.; Baer, Z. C.; Gross, E.; Padmanaban, S.; Goulas, K.; Gunbas, G.; Alayoglu, S.; Blanch, H. W.; Clark, D. S.; Toste, F. D. Chemocatalytic upgrading of tailored fermentation products toward biodiesel. ChemSusChem 2014, 7, 2445-2448.

(18) Goulas, K. A.; Sreekumar, S.; Song, Y.; Kharidehal, P.; Gunbas, G.; Dietrich, P. J.; Johnson, G. R.; Wang, Y. C.; Grippo, A. M.; Grabow, L. C.; Gokhale, A. A.; Toste, F. D. Synergistic Effects in Bimetallic Palladium-Copper Catalysts Improve Selectivity in Oxygenate Coupling Reactions. J. Am. Chem. Soc. 2016, 138, 6805-6812.

(19) Goulas, K. A.; Song, Y.; Johnson, G. R.; Chen, J. P.; Gokhale, A. A.; Grabow, L. C.; Toste, F. D. Selectivity tuning over monometallic and bimetallic dehydrogenation catalysts: effects of support and particle size. Catal. Sci. Technol. 2018, 8, 314-327.

(20) Goulas, K. A.; Gunbas, G.; Dietrich, P. J.; Sreekumar, S.; Grippo, A.; Chen, J. P.; Gokhale, A. A.; Toste, F. D. ABE Condensation over Monometallic Catalysts: Catalyst Characterization and Kinetics. ChemCatChem 2017, 9, 677-684.

(21) Xu, G.; Li, Q.; Feng, J.; Liu, Q.; Zhang, Z.; Wang, X.; Zhang, X.; $\mathrm{Mu}, \mathrm{X}$. Direct $\alpha$-Alkylation of Ketones with Alcohols in Water. ChemSusChem 2014, 7, 105-109.

(22) Liu, Q.; Xu, G.; Wang, X.; Liu, X.; Mu, X. Highly selective Upgrading of Biomass-Derived Alcohol Mixtures for Jet/Diesel-Fuel Components. ChemSusChem 2016, 9, 3465-3472.

(23) Kim, M.; Park, J.; Kannapu, H. P. R.; Suh, Y.-W. Cross-Aldol Condensation of Acetone and n-Butanol into Aliphatic Ketones over Supported Cu Catalysts on Ceria-Zirconia. Catalysts 2017, 7, 249-263.
(24) Nahreen, S.; Gupta, R. B. Conversion of the Acetone-ButanolEthanol (ABE) Mixture to Hydrocarbons by Catalytic Dehydration. Energy Fuels 2013, 27, 2116-2125.

(25) Vo, H. T.; Yeo, S. M.; Dahnum, D.; Jae, J.; Hong, C. S.; Lee, H. $\mathrm{Pd} / \mathrm{C}$-CaO-catalyzed $\alpha$-alkylation and hydrodeoxygenation of an acetone-butanol-ethanol mixture for biogasoline synthesis. Chem. Eng. J. 2017, 313, 1486-1493.

(26) Onyestyák, G.; Novodárszki, G.; Wellisch, Á. F.; Pilbáth, A. Upgraded biofuel from alcohol-acetone feedstocks over a two-stage flow-through catalytic system. Catal. Sci. Technol. 2016, 6, 4516-4524.

(27) Zhu, Q.; Shen, Ch.; Wang, J.; Tan, T. Upgrade of Solvent-Free Acetone-Butanol-Ethanol Mixtures to High Value Biofuels over NiContaining $\mathrm{MgO}-\mathrm{SiO}_{2}$ Catalysts with Greatly Improved WaterResistance. ACS Sustainable Chem. Eng. 2017, 5, 8181-8191.

(28) Ndaba, B.; Chiyanzu, I.; Marx, S. n-Butanol derived from biochemical and chemical routes: A review. Biotechnology Reports 2015, $8,1-9$.

(29) Barta, K.; Matson, T. D.; Fettig, M. L.; Scott, S. L.; Iretskii, A. V.; Ford, P. C. Catalytic disassembly of an organosolv lignin via hydrogen transfer from supercritical methanol. Green Chem. 2010, 12, 1640-1647.

(30) Barta, K.; Bottari, G.; Sun, Z. Supercritical methanol as solvent and carbon source in the catalytic conversion of 1,2-diaminobenzenes and 2-nitroanilines to benzimidazoles. Green Chem. 2015, 17, 51725181.

(31) Matson, T. D.; Barta, K.; Iretskii, A. V.; Ford, P. C. One-Pot Catalytic Conversion of Cellulose and of Woody Biomass Solids to Liquid Fuels. J. Am. Chem. Soc. 2011, 133, 14090-14097.

(32) Kumalaputri, A. J.; Bottari, G.; Erne, P. M.; Heeres, H. J.; Barta, K. Tunable and Selective Conversion of 5-HMF to 2,5-Furandimethanol and 2,5-Dimethylfuran over Copper-Doped Porous Metal Oxides. ChemSusChem 2014, 7, 2266-2275.

(33) Barta, K.; Ford, P. C. Catalytic Conversion of Nonfood Woody Biomass Solids to Organic Liquids. Acc. Chem. Res. 2014, 47, 15031512.

(34) Sun, Z.; Couto Vasconcelos, A.; Bottari, G.; Stuart, M. C. A.; Bonura, G.; Cannilla, C.; Frusteri, F.; Barta, K. Efficient Catalytic Conversion of Ethanol to 1-Butanol via the Guerbet Reaction over Copper- and Nickel-Doped Porous. ACS Sustainable Chem. Eng. 2017, 5, $1738-1746$

(35) Sun, Z.; Bottari, G.; Afanasenko, A.; Stuart, M. C. A.; Deuss, P. J.; Fridrich, B.; Barta, K. Complete lignocellulose conversion with integrated catalyst recycling yielding valuable aromatics and fuels. Nature Catalysis 2018, 1, 82-92.

(36) Cavani, F.; Trifirò, F.; Vaccari, A. Hydrotalcite-type anionic clays: Preparation, properties and applications. Catal. Today 1991, 11 (2), 173-301.

(37) Sheng, X.; Li, N.; Li, G.; Wang, W.; Yang, J.; Cong, Y.; Wang, A.; Wang, X.; Zhang, T. Synthesis of High Density Aviation Fuel with Cyclopentanol Derived from Lignocellulose. Sci. Rep. 2015, 5, 1-4.

(38) Abate, S.; Barbera, K.; Giglio, E.; Deorsola, F.; Bensaid, S.; Perathoner, S.; Pirone, R.; Centi, G. Synthesis, Characterization, and Activity Pattern of $\mathrm{Ni}-\mathrm{Al}$ Hydrotalcite Catalysts in $\mathrm{CO}_{2}$ Methanation. Ind. Eng. Chem. Res. 2016, 55, 8299-8308.

(39) Bian, L.; Wang, W.; Xia, R.; Li, Z. Ni-Based Catalyst Derived from $\mathrm{Ni} / \mathrm{Al}$ Hydrotalcite-like Compounds by the Urea Hydrolysis Method for CO Methanation. RSC Adv. 2016, 6, 677-686.

(40) Su, Q.; Gu, L.; Yao, Y.; Zhao, J.; Ji, W.; Ding, W.; Au, C.-T. Layered Double Hydroxides Derived $\mathrm{Ni}_{\mathrm{X}}\left(\mathrm{Mg}_{\mathrm{Y}} \mathrm{Al}_{\mathrm{Z}} \mathrm{O}_{\mathrm{N}}\right)$ Catalysts: Enhanced Ammonia Decomposition by Hydrogen Spillover Effect. Appl. Catal., B 2017, 201, 451-460.

(41) Sato, K.; Abe, N.; Kawagoe, T.; Miyahara, S.; Honda, K.; Nagaoka, K. Supported Ni Catalysts Prepared from Hydrotalcite-like Compounds for the Production of Hydrogen by Ammonia Decomposition. Int. J. Hydrogen Energy 2017, 42, 6610-6617.

(42) Li, G.; et al. Synthesis of diesel or jet fuel range cycloalkanes with 2-methylfuran and cyclopentanone from lignocellulose. Energy Fuels 2014, 28, 5112-5118. 